\title{
Risikofaktorer for blødende magesår
}

\begin{abstract}
Sammendrag
Bakgrunn. Mange legemidler gir økt risiko for blødende ulcus ventriculi og duodeni. Formålet med denne studien var å kartlegge medikamentbruk og Helicobacter pylori-infeksjon hos pasienter med blødende ulcus i 2002 og i 2007 og eventuelle endringer i medikamentbruk og forekomst av Helicobacter pylori mellom periodene.

Materiale og metode. Pasienter med blødende ulcus ventriculi og duodeni ble prospektivt inkludert i periodene 1.1.- 31.12. 2002 og 1.1.- 31.12. 2007. Bruk av ikke-steroide antiinflammatoriske midler (NSAID), acetylsalisylsyre, klopidogrel, lavmolekylært heparin, warfarin, selektive serotoninreopptakshemmere (SSRI), glukokortikoider, paracetamol og protonpumpehemmere samt Helicobacter pylori-infeksjon ble registrert. Befolkningen $\geq 60$ år i Oslo i 2007 var kontrollgruppe for medikamentforbruket.
\end{abstract}

Resultater. 78,2\% i 2002 og 90,7\% i 2007 brukte minst ett av medikamentene $(p=0,01)$. Ikke-selektive NSAIDmidler ble brukt av $25,7 \%$ i 2002 og av $46,1 \%$ i 2007 ( $p=0,001$ ). I 2002 brukte $36,7 \%$ to eller flere medikamenter, det samme gjaldt $50,9 \%$ i 2007 ( $p=0,02$ ).

Flere pasienter brukte ikke-steroide antiinflammatoriske midler, acetylsalisylsyre, klopidogrel, lavmolekylært heparin, selektive serotoninreopptakshemmere og glukokortikoider enn kontrollgruppen. Helicobacter pylori ble påvist hos $51,0 \%$ av pasientene i 2002 og hos $41,1 \%$ i 2007 ( $p=0,11)$.

Fortolkning. De fleste pasienter med blødende ulcus bruker medikamenter med kjent risiko for bivirkninger som ulcus ventriculi eller duodeni og/eller gastrointestinal blødning.

\section{Taran Søberg*}

taran.soberg@bluezone.no

Bjørn Hofstad

Gastromedisinsk avdeling

Leiv Sandvik

Seksjon for epidemiologi og statistikk

Maren Johansen*

RELIS Øst, legemiddelinformasjonssenter

Idar Lygren

Gastromedisinsk avdeling

Oslo universitetssykehus, Ullevål

0407 Oslo

\section{* Nåværende adresser: \\ T. Søberg, Medisinsk avdeling \\ Sykehuset Østfold Fredrikstad \\ 1603 Fredrikstad}

M. Johansen, Pronova BioPharma Norge AS Postboks 420

1327 Lysaker

Hematemese og melena er vanlige årsaker til akuttinnleggelse i sykehus. Peptisk ulcus i ventrikkel eller duodenum er ofte blødningskilden og påvises hos $40-50 \%$ av pasientene. I tillegg påvises erosjoner i ventrikkel eller duodenum hos 5-10\%. De viktigste risikofaktorene for ulcus og erosjoner er bruk av ikke-steroide antiinflammatoriske midler (NSAID) og infeksjon med Helicobacter pylori $(1,2)$. Blødning fra ulcus er en alvorlig komplikasjon med ca. $10 \%$ mortalitet (3).

Ikke-selektive NSAID-midler og acetylsalisylsyre hemmer enzymene cyklooksygenase-1 (COX-1) og cyklooksygenase-2 (COX-2). COX-1-hemming gir økt risiko både for slimhinneskade, i form av erosjoner og ulcus, og for blødning i gastrointestinaltractus. Risikoen øker ytterligere når de to midlene kombineres (4-8). Selektive COX2-hemmere (coxiber) har en slimhinnesparende effekt, men antakelig opprettholdes ikke denne når de brukes sammen med acetylsalisylsyre (4-8). Protonpumpehemmere reduserer risikoen for ulcus hos brukere av ikke-steroide antiinflammatoriske midler og acetylsalisylsyre $(1,9)$.

Bruk av platehemmere, antikoagulasjonsmidler og selektive serotoninreopptakshemmere (SSRI) øker faren for blødning fra erosjoner og ulcuser $(1,5,10-12)$. Systemiske glukokortikoider (steroider) gir økt risiko både for ulcus og for blødning fra eksisterende ulcuser. Det er også mulig at paracetamol gir slik økt risiko $(13,14)$. Når ett eller flere av disse medikamentene brukes sammen med ikke-steroide antiinflammatoriske midler og/eller acetylsalisylsyre, øker risikoen for blødende ulcus ventriculi eller duodeni betydelig $(5,9,12-15)$. Risikoen er størst hos eldre (6). I Norge øker forbruket av alle medikamentene som er omtalt over (16).

Prevalensen av Helicobacter pylori-infeksjon er raskt fallende $\mathrm{i}$ mange industrialiserte land, det gjelder både i befolkningen generelt og hos pasienter med ulcus ventriculi og duodeni (17). Tidligere ble Helicobacter pylori påvist hos over $90 \%$ av dem med ulcus duodeni og hos $70-80 \%$ av dem med ulcus ventriculi. I enkelte nyere studier er bakterien påvist hos under $50 \%$ av disse (18), og forekomsten av Helicobacter pylori er lavere ved blødende ulcus ventriculi og duodeni enn ved ukomplisert ulcus ventriculi og duodeni (2).

Hensikten med denne studien var å sammenlikne medikamentbruk og forekomst av Helicobacter pylori-infeksjon hos pasienter med blødende ulcus ventriculi og duodeni i 2002 og i 2007 - med særlig vekt på bruk av NSAID-preparater, kombinasjonsbruk av flere medikamenter med økt risiko for ulcus ventriculi og duodeni og/eller blødning samt bruk av protonpumpehemmere.

\section{Materiale og metode}

I perioden 1.1.-31.12. 2002 ble det ved gastromedisinsk avdeling ved Ullevål universitetssykehus gjort en prospektiv registrering av medikamentbruken hos pasienter med øvre gastrointestinalblødning (19). I perioden 1.1.-31.12. 2007 ble sykehusets pasienter

\section{Hovedbudskap}

- Pasienter med blødende magesår brukte i økende grad medikamenter med økt risiko for tilstanden

- Bruk av ikke-steroide antiinflammatoriske midler, acetylsalisylsyre, klopidogrel, lavmolekylært heparin, selektive serotoninreopptakshemmere og glukokortikoider var vanligere i pasientgruppen enn blant kontrollpersonene

- De fleste pasienter med blødende ulcus ventriculi og duodeni var eldre

- Flere pasienter bør få profylakse med protonpumpehemmer 
med gastrointestinalblødning prospektivt inkludert i prosjektet «Database over blødninger assosiert med legemidler, natur(lege)midler og helsekostpreparater", et samarbeid mellom RELIS Øst og gastromedisinsk avdeling. Fra oktober 2007 ble lokalbefolkningsgrunnlaget til sykehuset redusert fra ca. 190000 til ca. 160000 personer. Bortsett fra dette var pasientgrunnlaget likt $\mathrm{i}$ de to periodene.

Alle pasienter fra registreringen i 2002 og i 2007 som hadde hematemese og/eller melena og som ved gastroskopi fikk påvist ulcus eller erosjoner i ventrikkel og/eller duodenum, ble inkludert i vår studie. Pasienter ble ekskludert hvis de hadde malignt ulcus eller dersom supplerende koloskopi viste mulig blødningskilde. Ulcus ble definert som fibrinbelagte slimhinnelesjoner med tydelig dybde og diameter på minst $5 \mathrm{~mm}$. Erosjoner ble definert som fibrinbelagte slimhinnelesjoner med diameter $<5$ $\mathrm{mm}$ og $\geq 2 \mathrm{~mm}$ (9).

Alder, kjønn, endoskopisk diagnose, tidligere ulcus ventriculi eller duodeni, laveste hemoglobinverdi i blødningsforløpet, behov for blodtransfusjon, antall enheter SAGMAN-erytrocyttkonsentrat (SAG) transfundert og medikamentbruk forut for blødningen ble registrert under det aktuelle sykehusoppholdet. Mortalitet ble definert som død innen 30 dager etter initial blødning (3). Død og dødsårsak ble registrert av prosjektansvarlig lege minimum 30 dager etter blødningen.

Bruk av følgende medikamenter ble registrert: ikke-selektive NSAID-preparater, COX-2-hemmere (coxiber), acetylsalisylsyre, warfarin, klopidogrel, lavmolekylært heparin, systemiske glukokortikoider (steroider), selektive serotoninreopptakshemmere, paracetamol og protonpumpehemmere. Informasjon om medikamentbruken skrev seg fra journal og fra intervju av pasient og/eller pårørende. «Daglig medikamentbruk» ble definert som daglig bruk i to uker eller mer i perioden rett før blødningen. «Sporadisk bruk» ble definert som inntak minst én gang i løpet av de siste to uker. Sporadisk bruk av paracetamol ble ikke registrert.

«Kombinasjonsbruk av medikamenter» ble definert som samtidig bruk av to eller flere av studiemedikamentene, unntatt protonpumpehemmere og paracetamol. Med «samtidig bruk» menes daglig bruk av to eller flere av medikamentene eller daglig bruk av minst ett medikament og sporadisk bruk av ett eller flere medikamenter i samme periode. Hos pasienter som brukte warfarin, ble høyeste INR-verdi i blødningsforløpet registrert, og hos dem som brukte acetylsalisylsyre, ble daglig dose i milligram registrert.

Befolkningen $\geq 60$ år i Oslo i 2007 ble brukt som kontrollgruppe vedrørende medikamentbruk. Data om medikamentbruken i kontrollgruppen ble hentet fra reseptregiste- ret (20). Medikamentbruken hos pasientene $\geq 60$ år med blødende ulcus ventriculi eller duodeni i 2007 ble sammenliknet med medikamentbruken i kontrollgruppen. Dette ble bare giort for 2007, fordi reseptregisteret ikke var opprettet i 2002. Brukere i reseptregisteret defineres som personer som har hentet ut minst én resept på medikamentet $\mathrm{i}$ løpet av det aktuelle året.

Diagnostisering av Helikobacter pyloriinfeksjon ble gjort ved ${ }^{13} \mathrm{C}$ urea-pusteprøve eller serologisk prøve med kvantitering av antistoff mot Helicobacter pylori. De som ikke var blitt testet for Helicobacter pyloriinfeksjon under sykehusoppholdet, ble innkalt til poliklinisk ${ }^{13} \mathrm{C}$ urea-pusteprøve. De som etter purring ikke møtte, fikk brev med ferdig utfylt rekvisisjon fra sykehuset for serologisk prøve for Helicobacter pylori og anmodning om ta denne hos sin egen lege.

Sammenlikningen av variabler i pasientgruppene fra 2002 og fra 2007 ble testet med khikvadrattest, med 5\% signifikansnivå. På grunn av asymmetrisk distribusjon av data ble medianverdi beregnet for alder, $\mathrm{Hb}$, INR-verdi, antall enheter SAGMAN-blod transfundert og daglig dose acetylsalisylsyre. SPSS (versjon 16.0) ble brukt til statistiske analyser.

Beregning av standardiserte hendelsesrater (standardized event rates, SER) er basert på medikamentbruken hos pasientene $\geq 60$ år i 2007 og på medikamentbruken i kontrollgruppen. «Standardisert hendelsesrate» er observert antall medikamentbrukere i pasientgruppen dividert på forventet antall medikamentbrukere i pasientgruppen ut ifra medikamentbruken i kontrollgruppen justert for alder.

\section{Etikk}

Studien er godkjent av regional etisk komité for Helse Sør-Øst og av sykehusets personvernombud.

\section{Resultater}

128 pasienter (52 med ulcus duodeni, 48 med ulcus ventriculi, én pasient med både ulcus ventriculi og ulcus duodeni og 27 pasienter med erosjoner) ble inkludert i 2002. I 2007 ble 113 pasienter (52 med ulcus duodeni, 40 med ulcus ventriculi, 12 pasienter med både ulcus ventriculi og ulcus duodeni og ni med erosjoner) inkludert. Demografiske data vedrørende pasientene i begge perioder er fremstilt $\mathrm{i}$ tabell 1 . Ni pasienter $(7,0 \%)$ døde innen 30 dager i 2002, seks $(5,3 \%)$ døde innen 30 dager i 2007 . Kardiovaskulær sykdom var hyppigste dødsårsak $(\mathrm{n}=7)$

Medikamentbruken hos pasientene i periodene er fremstilt i tabell 2. I 2002 brukte $66,4 \%$ av pasientene ikke-steroide antiinflammatoriske midler eller acetylsalisylsyre eller en kombinasjon av disse medikamentene, $\operatorname{mot} 74,1 \%$ i 2007 ( $p=0,13)$. Både daglig og sporadisk bruk er tatt med. I 2002 var $80,4 \%$ og i $200780,8 \%$ av NSAID-bru- kerne dagligbrukere. Alle som tok acetylsalisylsyre var dagligbrukere. Det var flere pasienter som brukte ikke-selektive NSAIDmidler i 2007 (46,1 \%) enn i $2002(25,7 \%)$ $(\mathrm{p}=0,001)$. I 2002 tok $41,1 \%$ av NSAIDbrukerne coxiber, i $20073,8 \%(\mathrm{p}<0,001)$. $47,8 \%$ av coxibbrukerne i 2002 brukte også acetylsalisylsyre, mens ingen av dem som brukte coxiber i 2007 tok acetylsalisylsyre.

Kombinasjonsbruk av medikamenter (protonpumpehemmere og paracetamol ikke medregnet) økte fra $2002(36,7 \%)$ til 2007 $(50,9 \%)(\mathrm{p}=0,02)$. Andelen pasienter som ikke brukte noen av de aktuelle medikamentene (protonpumpehemmere ikke medregnet) var lavere i $2007(9,3 \%)$ enn i 2002 $(21,8 \%)(\mathrm{p}=0,01)(\operatorname{tab} 2)$.

Det var en statistisk signifikant økning i bruk av lavmolekylært heparin, klopidogrel og steroider fra 2002 til 2007 (tab 2). Alle som fikk klopidogrel var dagligbrukere. $\mathrm{Ni}$ av 21 pasienter $(42,8 \%)$ som brukte lavmolekylært heparin og 23 av 31 (74,2\%) som brukte steroider, hadde gjort det $\mathrm{i}$ under to uker.

Det var ingen statistisk signifikant forskjell i bruk av acetylsalisylsyre, warfarin, selektive serotoninreopptakshemmere, protonpumpehemmer og paracetamol mellom pasientene i 2002 og pasientene i 2007 (tab 2). Alle som fikk disse midlene var dagligbrukere. Til sammen 13 pasienter brukte protonpumpehemmere, hvorav ti $(83,3 \%)$ var dagligbrukere.

Sammenliknet med kontrollgruppen brukte pasienter $\geq 60$ år med blødende ulcus ventriculi og duodeni i 2007 statistisk signifikant mer ikke-steroide antiinflammatoriske midler, acetylsalisylsyre, klopidgrel, lavmolekylært heparin, selektive serotoninreopptakshemmere og steroider. Det var ingen statistisk signifikant forskjell i bruk av warfarin, protonpumpehemmer og paracetamol (tab 3).

96 pasienter $(75,0 \%)$ i 2002 og 95 pasienter $(84,1 \%)$ i 2007 ble testet for Helicobacter pylori-infeksjon. Bakterien ble påvist hos 49 av de $96(51,0 \%)$ i 2002 og hos 39 av de $95(41,1 \%)$ i $2007(\mathrm{p}=0,11) .43$ pasienter $(33,6 \%)$ i 2002 og 28 pasienter $(25,9 \%)$ i 2007 brukte ikke ikke-steroide antiinflammatoriske midler eller acetylsalisylsyre (tab 2). Av disse ble 37 i 2002 og 23 i 2007 testet for Helicobacter pylori-infeksjon. Hos dem som ikke brukte NSAID-midler eller acetylsalisylsyre ble bakterien påvist hos 25 $(67,6 \%)$ i 2002 og hos $11(47,8 \%)$ i 2007 $(\mathrm{p}=0,19)$.

\section{Diskusjon}

De fleste med blødende ulcus ventriculi og duodeni brukte medikamenter som er kjent for å øke risikoen for ulcus og/eller gastrointestinal blødning. Pasientene brukte mer av disse medikamentene enn tilsvarende aldersgruppe i befolkningen, hvilket taler for at medikamentene var medvirkende årsak til 
at de fikk blødende ulcus. Fra 2002 til 2007 var det en tendens til økende medikamentbruk. Det er kjent at alder er en viktig risikofaktor for medikamentutløst peptisk ulcus (6), og vår studie viser at det særlig er eldre som får blødende ulcus ventriculi og duodeni.

Ikke-steroide antiinflammatoriske midler Våre pasienter med blødende ulcus ventriculi og duodeni brukte betydelig mer ikkesteroide antiinflammatoriske midler enn tilsvarende aldersgruppe $\mathrm{i}$ befolkningen $(\mathrm{SER}=2,2)$. Omtrent to tredeler av pasientene i begge perioder brukte ikke-steroide antiinflammatoriske midler, acetylsalisylsyre eller en kombinasjon av disse. Mindre bruk av coxiber i Norge har ført til en tilsvarende økning i bruken av ikke-selektive NSAID-midler (16), og dette gjenspeiles i vårt materiale. I 2002 brukte $41 \%$ av NSAID-brukerne coxiber, mens markedsandelen samme år var 35,7\% (16). Det var uventet mange brukere av coxiber $i$ vår studie i $2002(4,8)$. Imidlertid brukte mange av dem $(47,8 \%)$ acetylsalsylsyre i tillegg. Samtidig bruk av acetylsalsylsyre ser ut til å oppveie coxibenes fordeler når det gjelder slimhinneskade i gastrointestinaltractus (8, 21).

\section{Profylakse med protonpumpehemmer}

Samtidig bruk av protonpumpehemmer reduserer risikoen for ulcus med $60-70 \%$ hos brukere av ikke-steroide antiinflammatoriske midler og/eller acetylsalisylsyre (22). Mange av våre pasienter hadde økt risiko for ulcus og blødning og burde fått profylakse med protonpumpehemmer. Man kunne derfor forvente at disse brukte mer slike midler enn tilsvarende aldersgruppe i befolkningen, men i 2007 brukte pasientene mindre enn kontrollgruppen $\quad(\mathrm{SER}=0,58, \quad 95 \% \quad \mathrm{KI}$ $0,25-1,26, \mathrm{p}=0,33)$

I 2008 kom det i USA retningslinjer for profylakse med protonpumpehemmer hos dem som får ikke-steroide antiinflammatoriske midler og/eller platehemmere. Der anbefaler man profylaktisk bruk av protonpumpehemmer i langt større grad enn det som er vanlig i Norge (23). Det er behov for norske retningslinjer vedrørende profylakse med protonpumpehemmer hos dem som bruker NSAID-midler og/eller platehemmere.

\section{Platehemmere og antikoagulasjonsmidler}

Økt bruk av acetylsalisylsyre de siste 10-20 årene har resultert $i$ at dette midlet er blitt en viktigere årsak til ulcus og gastrointestinal blødning enn tidligere. Både i vår studie og i tilsvarende studier fra utlandet var ca. $40 \%$ av pasientene brukere $(24,25)$. De som tar acetylsalisylsyre og/eller ikke-steroide antiinflammatoriske midler har ofte erosjoner eller ulcerasjoner i slimhinnen i gastrointestinaltractus (26). Et økende antall av disse pasientene får behandling med ytterligere platehemming og/eller antikoagulasjons- midler. Dette gjenspeiles i vår studie i form av en økning i bruken av lavmolekylært heparin og klopidogrel fra 2002 til 2007. Disse medikamentene øker faren for blødning fra allerede eksisterende erosjoner og ulcus. I tillegg kan klopidogrel hemme tilheling av slike slimhinnelesjoner (23).

I Norge er det ikke vanlig å gi profylakse med protonpumpehemmer til dem som får flere platehemmere eller en kombinasjon av platehemmer(e) og lavmolekylært heparin eller warfarin, men langt flere bør få slik profylakse (23). Til dem som bruker klopidogrel bør man velge pantoprazol eller lansoprazol, siden de andre protonpumpehemmerne på markedet ser ut til å redusere effekten av klopidogrel (27).

Etter en del ortopediske inngrep gis det lavmolekylært heparin daglig i flere uker. Pasientene bruker også ofte ikke-steroide antiinflammatoriske midler, mange også acetylsalisylsyre. Både i 2002 og i 2007 tilhørte omtrent halvparten av heparinbrukerne i vårt materiale denne pasientgruppen. Det er kjent at disse pasientene har overhyppighet av gastrointestinal blødning. Man bør derfor vurdere å gi dem protonpumpehemmer i den postoperative perioden (28).

\section{Glukokortikoider (steroider)}

Pasientene i vår studie brukte også betydelig mer steroider enn kontrollgruppen (SER = $2,8)$. Det er kjent at disse øker faren for ulcus og gastrointestinal blødning, særlig hos dem som også bruker ikke-steroide antiinflammatoriske midler eller acetylsalisylsyre (14, 29). Ved oppstart av steroidbehandling bør man alltid vurdere om pasienten også trenger profylakse med protonpumpehemmer (23).

Tabell 1 Pasienter med hematemese og/eller melena som fikk påvist ulcus eller erosjoner i ventrikkel og/eller duodenum ved gastromedisinsk avdeling, Ullevål universitetssykehus i 2002 og i 2007

\begin{tabular}{lcc} 
& 2002 (n = 128) & 2007 (n = 113) \\
\hline Median alder (år) (spredning) & $75(18-97)$ & $76(18-96)$ \\
Menn/kvinner (prosentandel menn) & $61 / 67(47,6)$ & $58 / 55(51,3)$ \\
\hline Tidligere ulcus (\%) & $29(22,7)$ & $22(19,5)$ \\
Median hemoglobin g/100 ml (spredning) & $7,9(4,0-17,0)$ & $8,0(3,5-14,4)$ \\
\hline Antall som fikk blodtransfusjon (\%) & $90(70,3)$ & $83(73,5)$ \\
\hline Mediant antall SAG-enheter transfundert' ${ }^{1}$ (spredning) & $4,0(1-27)$ & $4,0(1-16)$ \\
\hline Mediant INR-nivå2 (spredning) & $3,3(1,6-8,0)$ & $4,0(1,2-8,0)$ \\
\hline Median dose acetylsalisylsyre i mg ${ }^{3}$ (spredning) & $75(75-160)$ & $75(75-160)$
\end{tabular}

1 Gjelder pasienter som fikk blodtransfusjon ( $n=90$ i 2002, $n=83$ i 2007)

${ }^{2}$ Gjelder pasienter som brukte warfarin $(n=21$ i $2002, n=15$ i 2007)

${ }^{3}$ Gjelder pasienter som brukte acetylsalisylsyre ( $n=48$ i 2002, $n=42$ i 2007)

Tabell 2 Medikamentbruk hos pasienter med hematemese og/eller melena som fikk påvist ulcus eller erosjoner i ventrikkel og/eller duodenum i hhv. 2002 og 2007. Både daglig og sporadisk bruk er medregnet

\begin{tabular}{|lcrr} 
& $2002(\mathrm{n}=128)$ & $2007(\mathrm{n}=108)^{1}$ & P-verdi \\
\hline Total NSAID-bruk (\%) & $56(43,7)$ & $52(48,1)$ & 0,293 \\
\hline ikke-selektive NSAID-midler (\%) & $33(25,7)$ & $50(46,1)$ & 0,001 \\
\hline coxiber (\%) & $23(17,9)$ & $2(1,9)$ & $<0,001$ \\
\hline Acetylsalisylsyre (\%) & $48(37,5)$ & $42(38,9)$ & 0,466 \\
\hline Warfarin (\%) & $21(16,4)$ & $15(13,7)$ & 0,363 \\
\hline Klopidogrel (\%) & $0(0)$ & $7(6,4)$ & 0,004 \\
\hline Lavmolekylært heparin (\%) & $6(4,7)$ & $15(13,9)$ & 0,012 \\
\hline Selektive serotoninreopptakshemmere (\%) & $19(14,8)$ & $17(15,7)$ & 0,495 \\
\hline Steroider (\%) & $11(8,5)$ & $20(18,5)$ & 0,020 \\
\hline Protonpumpehemmer (\%) & $6(4,7)$ & $7(6,4)$ & 0,374 \\
\hline Paracetamol (\%) ${ }^{2}$ & $38(29,7)$ & $35(32,4)$ & 0,378 \\
\hline To eller flere medikamenter ${ }^{3}(\%)$ & $47(36,7)$ & $55(50,9)$ & 0,020 \\
\hline NSAID-midler og/eller acetylsalisylsyre $(\%)$ & $85(66,4)$ & $80(74,1)$ & 0,128 \\
\hline Ingen medikamenter ${ }^{4}$ & $28(21,8)$ & $10(9,3)$ & 0,014
\end{tabular}

1 Opplysninger om medikamentbruk foreligger hos 108 av 113 pasienter

2 Sporadisk bruk av paracetamol ble ikke registrert

${ }^{3}$ Protonpumpehemmer og paracetamol ikke medregnet

${ }_{4}^{4}$ Protonpumpehemmer ikke medregnet 
Tabell 3 Medikamentbruk hos pasienter $\geq 60$ år med hematemese og/eller melena som fikk påvist ulcus eller erosjoner i ventrikkel og/eller duodenum i 2007 sammenliknet med kontrollgruppe

\begin{tabular}{|c|c|c|c|c|c|c|}
\hline & $\begin{array}{l}\text { Pasienter } \\
\text { (n = 82) }\end{array}$ & $\begin{array}{l}\text { Kontollgruppe }{ }^{1} \\
(n=98240)\end{array}$ & $\begin{array}{l}\text { Forven- } \\
\text { tet antall } \\
\text { brukere }^{2}\end{array}$ & $\mathrm{SER}^{3}$ & $95 \% \mathrm{KI}$ & P-verdi \\
\hline NSAID-midler (\%) & $37(45,1)$ & $24046(24,5)$ & 17,1 & 2,2 & $1,6-3,1$ & $<0,001$ \\
\hline $\begin{array}{l}\text { Ikke-selektive } \\
\text { NSAID-midler (\%) }\end{array}$ & $35(42,6)$ & $22865(23,3)$ & 16,3 & 2,1 & $1,5-3,0$ & $<0,001$ \\
\hline Coxiber (\%) & $2(2,4)$ & $1181(1,2)$ & 0,8 & 2,5 & $0,0-8,0$ & 0,053 \\
\hline Acetylsalisylsyre (\%) & $39(47,6)$ & $25080(25,5)$ & 25,2 & 1,5 & $1,2-1,9$ & 0,004 \\
\hline Warfarin (\%) & $14(17,1)$ & $6905(7,0)$ & 8,1 & 1,7 & $0,9-3,1$ & 0,132 \\
\hline Klopidogrel (\%) & $7(8,5)$ & $1591(1,6)$ & 1,5 & 4,7 & $2,4-9,8$ & $<0,001$ \\
\hline $\begin{array}{l}\text { Lavmolekylært } \\
\text { heparin (\%) }\end{array}$ & $13(15,9)$ & $1574(1,6)$ & 1,4 & 9,3 & $5,0-16,1$ & $<0,001$ \\
\hline SSRI (\%) & $12(14,6)$ & $5650(5,8)$ & 5,1 & 2,4 & $1,3-4,4$ & 0,002 \\
\hline Steroider (\%) & $17(20,7)$ & $6381(6,5)$ & 6,1 & 2,8 & $1,8-4,5$ & $<0,001$ \\
\hline $\begin{array}{l}\text { Protonpumpehemmer } \\
\text { (\%) }\end{array}$ & $5(6,0)$ & $9368(9,5)$ & 8,6 & 0,58 & $0,25-1,26$ & 0,331 \\
\hline Paracetamol (\%) & $26(31,7)$ & $27171(27,7)$ & 26,3 & 0,99 & $0,61-1,37$ & 0,974 \\
\hline \multicolumn{7}{|c|}{$\begin{array}{l}{ }^{1} \text { Befolkningen } \geq 60 \text { år i Oslo, data fra reseptregisteret } 2007 \\
{ }^{2} \text { Forventet antall medikamentbrukere i pasientgruppen ut fra medikamentbruken i kontrollgruppen justert } \\
\text { for alder } \\
{ }^{3} \text { SER (standardized event rate): observert antall medikamentbrukere i pasientgruppen dividert på forventet } \\
\text { antall medikamentbrukere i pasientgruppen ut fra medikamentbruken i kontrollgruppen }\end{array}$} \\
\hline
\end{tabular}

\section{Selektive serotoninreopptakshemmere}

Ca. $15 \%$ av våre pasienter, i begge perioder, brukte selektive serotoninreopptakshemmere. Forbruket var betydelig høyere enn i kontrollgruppen (SER $=2,4)$. Det er mange eldre brukere, og blødningsrisikoen ved bruk av disse medikamentene er lite påaktet. Selektive serotoninreopptakshemmere brukt alene gir to til tre ganger økt risiko for gastrointestinal blødning. Når de kombineres med acetylsalisylsyre eller ikke-steroide antiinflammatoriske midler, er risikoen betydelig høyere (30).

\section{Paracetamol}

Det ble i 2002 publisert en epidemiologisk studie som viste at de som bruker $\geq 2$ g paracetamol daglig, har økt risiko for gastrointestinal blødning (13). Ca. 30\% av våre pasienter, i begge perioder, brukte paracetamol. Dette er på samme nivå som forbruket i kontrollgruppen (SER $=0,99)$, hvilket taler imot at dette midlet var medvirkende årsak til at pasientene utviklet blødende ulcus.

\section{Kombinasjoner av medikamenter}

Det var økning i kombinasjonsbruk av to eller flere medikamenter fra 2002 til 2007 $(p=0,02)$. Det er kjent at ikke-steroide antiinflammatoriske midler kombinert med andre legemidler kan gi interaksjoner som medfører betydelig økt risiko for bivirkninger. Hvis brukere av NSAID-midler eller acetylsalisylsyre i tillegg får steroider, platehemmer, antikoagulasjonsmidler eller selektive serotoninreopptakshemmere, kan de komme over i en høyrisikogruppe. Ikke-steroide antiinflammatoriske brukt alene gir omtrent fire ganger økt risiko for blødende ulcus ventriculi og duodeni (6), mens kombinasjonsbruk av slike midler og selektive serotoninreopptakshemmere gir 12-15 ganger økt risiko (30). Kombinasjonsbruk av NSAID-midler og acetylsalisylsyre eller antikoagulasjonsmidler gir $10-15$ ganger økt risiko $(6,31)$. Kombinasjonsbruk av NSAID-midler og steroider gir fire ganger høyere risiko enn NSAID-midler brukt alene (1).

\section{Helicobacter pylori}

Det var ingen statistisk signifikant endring $i$ forekomsten av Helicobacter pylori fra 2002 til 2007. Trenden var imidlertid at andelen pasienter med slik infeksjon var synkende, det gjaldt også for dem som ikke brukte acetylsalisylsyre og/eller ikke-steroide antiinflammatoriske midler. Prevalensen av Helicobacter pylori-infeksjon i befolkningen i Oslo i den aktuelle tidsperioden er ukjent, vi vet derfor ikke om det hos våre pasienter var en overhyppighet av infeksjonen eller ikke. I to norske befolkningsstudier, fra 1995-97 og 2004, var prevalensen av Helicobacter Median alder i disse studiene var imidlertid lavere enn hos våre pasienter, og det er kjent at prevalensen av Helicobacter pylori i befolkningen øker med stigende alder (18).

Tidligere var Helicobacter pylori-infeksjon viktigste årsak til peptisk ulcus, og $70-80 \%$ av disse pasientene hadde ulcus duodeni. Etter hvert som medikamenter har fått økende betydning som årsak, har andelen med ulcus ventriculi økt (2), slik vi også ser i vår studie. pylori henholdsvis $37 \%$ og $25 \%(32,33)$.

\section{Konklusjon}

De fleste pasienter med blødende ulcus ventriculi og duodeni er eldre og bruker medikamenter med kjent økt risiko for bivirkninger som ulcus og/eller gastrointestinal blødning. De siste fem år har det vært en tendens til økning i bruken av ikke-selektive NSAIDmidler og økt kombinasjonsbruk av medikamenter. Pasienter med blødende ulcus ventriculi og duodeni bruker mer ikke-steroide antiinflammatoriske midler, acetylsalisylsyre, klopidogrel, lavmolekylært heparin, selektive serotoninreopptakshemmere og steroider enn tilsvarende aldersgruppe i befolkningen. Pasienter som bruker ett eller flere av disse medikamentene bør vurderes for profylaktisk behandling med protonpumpehemmer. Helicobakter pylori-infeksjon påvises nå hos rundt $50 \%$ av dem med blødende ulcus ventriculi og duodeni.

Oppgitte interessekonflikter: Taran Søberg har fått økonomisk støtte fra AstraZeneca i forbindelse med deltakelse på UEGW (United European Gastroenterology Week) i Paris 2007. De andre forfatterne har ingen oppgitte interessekonflikter.

\section{Litteratur}

1. Lanza FL. A guideline for the treatment and prevention of NSAID-induced ulcers. Members of the Ad Hoc Committee on Practice Parameters of the American College of Gastroenterology. Am J Gastroenterol 1998; 93: 2037-46.

2. Van Leerdam ME, Tytgat GN. Helicobacter pylori infection in peptic ulcer haemorrhage. Aliment Pharmacol Ther 2002; 16 (suppl 1): 66-78.

3. Rockall TA, Logan RF, Devlin HB et al. Incidence of and mortality from acute upper gastrointestinal haemorrhage in the United Kingdom. Steering committee and members of the National Audit of Acute Upper Gastrointestinal Haemorrhage. BMJ 1995; 311: 222-6.

4. Bombardier C, Laine L, Reicin A et al. Comparison of upper gastrointestinal toxicity of rofecoxib and naproxen in patients with rheumatoid arthritis. VIGOR Study Group. N Engl J Med 2000; 343: 1520-8.

5. Derry S, Loke YK. Risk of gastrointestinal haemorrhage with long term use of aspirin: metaanalysis. BMJ 2000; 321: 1183-7.

6. Hernandez-Diaz S, Rodriguez LA. Association between nonsteroidal anti-inflammatory drugs and upper gastrointestinal tract bleeding/perforation: an overview of epidemiologic studies published in the 1990s. Arch Intern Med 2000; 160: 2093-9.

7. Langman MJ, Jensen DM, Watson DJ et al. Adverse upper gastrointestinal effects of rofecoxib compared with NSAIDs. JAMA 1999; 282: 1929-33.

8. Silverstein FE, Faich G, Goldstein JL et al. Gastrointestinal toxicity with celecoxib vs nonsteroidal anti-inflammatory drugs for osteoarthritis and rheumatoid arthritis: the CLASS study: a randomized controlled trial. Celecoxib Long-term Arthritis Safety Study. JAMA 2000; 284: 1247-55.

9. Graumlich JF. Preventing gastrointestinal complications of NSAIDs. Risk factors, recent advances, and latest strategies. Postgrad Med 2001; 109: $117-8$.

10. CAPRIE Steering Committee. A randomised, blinded trial of clopidogrel versus asprin in patients at risk of ischemic events (CAPRIE). Lancet 1996; 348: 1329-39.

11. de Abajo FJ, Rodriguez LA, Montero D. Association between selective serotonin reuptake inhibitors and upper gastrointestinal bleeding: population based case-control study. BMJ 1999; 319: 1106-9

12. Johnsen SP, Sørensen HT, Mellemkjær L et al. Hospitalisation for upper gastrointestinal bleeding associated with use of oral anticoagulants. Thromb Haemost 2001; 86: 563-8. 
13. Garcia Rodriguez LA, Hernandez-Diaz S. Relative risk of upper gastrointestinal complications among users of acetaminophen and nonsteroidal anti-inflammatory drugs. Epidemiology 2001; 12: 570-6.

14. Nielsen GL, Sørensen HT, Mellemkjær L et al. Risk of hospitalization resulting from upper gastrointestinal bleeding among patients taking corticosteroids: a register-based cohort study. Am J Med 2001; 111: $541-5$

15. Hylek EM, Heiman H, Skates SJ et al. Acetaminophen and other risk factors for excessive warfarin anticoagulation. JAMA 1998; 279: 657-62.

16. Nasjonalt folkehelseinstitutt. Legemiddelforbruket i Norge. www.legemiddelforbruk.no (1.4.2008).

17. Pounder RND. The prevalence of Helicobacter pylori infection in different countries. Aliment Pharmacol Ther 21995; 9 (suppl 2): 33-9.

18. Chiorean MV, Locke GR, Zinsmeister AR et al. Changing rates of Helicobacter pylori testing and treatment in patients with peptic ulcer disease. Am J Gastroenterol 2002; 97: 3015-22.

19. Søberg T, Hofstad B, Lygren I. Medication in patients with upper gastrointestinal bleeding. Abstrakt. Scand J Gastroenterol 2004; 39 (suppl 240): 48.

20. Nasjonalt folkehelseinstitutt. Nasjonalt reseptbasert legemiddelregister. www.reseptregisteret.no (30.4.2008)

21. Nathan JP, Castellanos JT, Rosenberg JM et al. Impact of aspirin on the gastrointestinal-sparing effects of cyclooxygenase-2 inhibitors. Am J Health Syst Pharm 2003; 60: 392-4.

22. Laine L. Proton pump inhibitor co-therapy with nonsteroidal anti-inflammatory drugs - nice or necessary? Rev Gastroenterol Disord 2004; 4 (suppl 4): 33-41.

23. Bhatt DL, Scheiman J, Abraham NS et al. ACCF/ ACG/AHA 2008 expert consensus document on reducing the gastrointestinal risks of antiplatelet therapy and NSAID use: a report of the American College of Cardiology Foundation Task Force on Clinical Expert Consensus Documents. J Am Coll Cardiol 2008; 52: 1502-17.

24. Garcia Rodriguez LA, Hernandez-Diaz S, de Abajo FJ. Association between aspirin and upper gastrointestinal complications: systematic review of epidemiologic studies. Br J Clin Pharmacol 2001; 52: 563-71.

25. Garcia Rodriguez LA, Hernandez-Diaz S. Risk of uncomplicated peptic ulcer among users of aspirin and nonaspirin nonsteroidal antiinflammatory drugs. Am J Epidemiol 2004; 159: 23-31.

26. Laine $L$. The gastrointestinal effects of nonselective NSAIDs and COX-2-selective inhibitors. Semin Arthritis Rheum 2002; 32 (suppl 1): 25-32.

27. Juurlink DN, Gomes T, Ko DT et al. A populationbased study of the drug interaction between proton pump inhibitors and clopidogrel. CMAJ 2009; 180: 713-8.

28. Sharma S. Upper gastrointestinal bleeding after hip and knee arthroplasty. Orthopedics 2006; 29 : 255-7.

29. Hernandez-Diaz S, Rodriguez LA. Steroids and risk of upper gastrointestinal complications. Am J Epidemiol 2001; 153: 1089-93.

30. Dalton SO, Johansen C, Mellemkjaer L et al. Use of selective serotonin reuptake inhibitors and risk of upper gastrointestinal tract bleeding: a population-based cohort study. Arch Intern Med 2003; 163: 59-64.

31. Lanas A, Garcia-Rodriguez LA, Arroyo MT et al. Risk of upper gastrointestinal ulcer bleeding associated with selective cyclo-oxygenase- 2 inhibitors, traditional non-aspirin non-steroidal anti-inflammatory drugs, aspirin and combinations. Gut 2006; 55: $1731-8$.

32. Nordenstedt H, Nilson M, Johnsen R et al. Helicobacter pylori infection and gastrointestinal reflux in a population-based study (the HUNT study). Helicobacter 2007; 12: 16-22.

33. Asfeldt AM, Straume B, Erikson Steigen $S$ et al. Changes in the prevalence of dyspepsia and Helicobacter pylori infection after 17 years: the Sørreisa gastrointestinal disorder study. Eur J Epidemiol 2008; 23: 625-33. 